\title{
Identification of a bone marrow-derived mesenchymal progenitor cell subset that can contribute to the gastric epithelium
}

\author{
Tomoyuki Okumura ${ }^{1,3}$, Sophie SW Wang ${ }^{1,4}$, Shigeo Takaishi ${ }^{1}$, Shui Ping Tu', Vivian $\mathrm{Ng}^{1}$, Russell E Ericksen ${ }^{1}$, \\ Anil K Rustgi ${ }^{2}$ and Timothy C Wang ${ }^{1}$
}

Recent studies with Helicobacter-infected mice have shown that bone marrow-derived cells can repopulate the gastric epithelium and progress to cancer. However, it has not been established which cellular subset can potentially contribute to the epithelium. The aim of this study was to investigate the ability of bone marrow-derived mesenchymal stem cells (MSCs) that express cytokeratin 19 (K19) to contribute to the gastric epithelium. MSCs cultures were established from whole bone marrow and expression of K19 was detected in a minority (1 of 13) of clones by real-time PCR and immunostaining. Transfection of a K19-green fluorescent protein (GFP) vector and isolation of GFP-expressing colonies generated high K19-expressing MSC clones (K19GFPMSC). Incubation of MSCs with gastric tissue extract markedly induced mRNA expression of gastric phenotypic markers and was observed to a greater extent in K19GFPMSCs compared with parental MSCs and mock transfectants. Both K19GFPMSCs and GFP-labeled control MSCs gave rise to gastric epithelial cells after injection into the murine stomach. In addition, after blastocyst injections, K19GFPMSCs gave rise to GFP-positive gastric epithelial cells in all 13 pups, whereas only 3 of 10 offspring showed GFP-positive gastric epithelial cells after injection of GFP-labeled control MSCs. Although K19 expression could not be detected in murine whole bone marrow, $H$. felis infection increased K19-expressing MSCs in the circulation. Taken together, our results show that bone marrow-derived MSCs can contribute to the gastric epithelium. The K19-positive MSC fraction that is induced by chronic $H$. felis infection appears to be the important subset in this process.

Laboratory Investigation (2009) 89, 1410-1422; doi:10.1038/labinvest.2009.88; published online 19 October 2009

KEYWORDS: bone marrow-derived cells; cytokeratin 19; differentiation; gastric epithelium; mesenchymal stem cells

There is considerable evidence that bone marrow-derived cells (BMDCs) show plasticity. Studies in gender-mismatched human bone marrow transplant recipients have provided evidence that BMDCs contribute to the epithelium of the liver, ${ }^{1}$ lung, ${ }^{2,3}$ and gastrointestinal tract. ${ }^{4-8}$ Furthermore, bone marrow transplant experiments in mice have shown that engraftment of BMDCs in epithelial tissues supports maintenance of the epithelium and aids in tissue healing. ${ }^{2,9-13}$ Work from our laboratory provided the first clear evidence of the contribution of BMDCs to the development of cancer. In mice reconstituted with labeled bone marrow, chronic Helicobacter felis ( $H$. felis) infection induced repopulation of the gastric epithelium with BMDCs and progression of these cells to intraepithelial cancer. ${ }^{14}$ BMDCs have also been detected in human epithelial neoplasias such as renal cell carcinoma, ${ }^{15}$ colon adenoma, ${ }^{16}$ and lung cancer ${ }^{16,17}$ in patients who have undergone a previous bone marrow transplant.

In the majority of bone marrow transplant studies in mice and humans, whole bone marrow cells or the enriched hematopoietic stem cell fraction were used to reconstitute the recipients' bone marrow. However, in most cases, the infused donor cells were heterogeneous and it remains uncertain which cellular subset within the graft actually contributed to the epithelial lineage. ${ }^{8,18}$ In our previous study, the mesenchymal stem cell (MSC) fraction of bone marrow was proposed to be a possible source of engrafted BMDCs

\footnotetext{
${ }^{1}$ Division of Digestive and Liver Diseases, Department of Medicine, Columbia University Medical Center, New York, NY, USA; ${ }^{2}$ Department of Medicine and Department of Genetics, University of Pennsylvania, Philadelphia, PA, USA; ${ }^{3}$ Department of Surgery and Department of Science, Graduate School of Medicine and Pharmaceutical Sciences, University of Toyama, Toyama, Japan and ${ }^{4}$ Division of Gastroenterology, Department of Internal medicine, Kaohsiung Medical University Hospital, Kaohsiung, Taiwan Correspondence: Dr TC Wang, MD, Division of Digestive and Liver Diseases, Department of Medicine, Columbia University Medical Center, 1130 St. Nicholas Avenue, Room 925, 9th Floor, New York, NY, USA.
}

E-mail: tcw21@columbia.edu

Received 25 December 2008; revised 8 May 2009; accepted 3 June 2009 
because induction of gastric epithelial phenotype markers after treatment with gastric tissue extract was detected in this fraction, but not in the HSC fraction. ${ }^{14}$ Nevertheless, direct evidence that MSCs contribute to the gastric epithelium has not been established.

MSCs constitute only a small fraction of the bone marrow $^{19,20}$ and originally were characterized as colonyforming fibroblast-like cells ${ }^{19,21,22}$ that adhered to plastic in culture and possess the ability to differentiate into osteocytes, chondrocytes, adipocytes. ${ }^{20,23}$ Studies in humans and animals have also reported the in vitro differentiation of MSCs into endodermal, ectodermal, and mesodermal tissues, such as pneumocytes ${ }^{24}$ and hepatocytes, ${ }^{25}$ neural cells, ${ }^{26}$ and cardiomyocytes, ${ }^{27}$ respectively. More recently, the pluripotency of MSCs has been shown in vivo. ${ }^{28-30}$

In addition to their potential for differentiation into both mesodermal and endodermal lineage, some multipotent MSC subsets have been shown to express endoderm-associated genes such as cytokeratins and Sox 17. ${ }^{29,31,32}$ Cytokeratins are a family of intermediate filaments that are expressed in epithelial cells and appear to be critical for the maintenance of the cytoskeleton. ${ }^{33}$ Among the various cytokeratins, keratin 19 (K19) has been reported to be expressed in the progenitor zone of the epidermis ${ }^{34}$ and the proliferative zone of the gastrointestinal tract, ${ }^{35-38}$ and is thought to be an early marker of epithelial cell lineage. ${ }^{39}$ Transgenic studies in mice have shown that K19 is expressed in the neck/isthmus region of the gastric glandular unit, the area where epithelial progenitors and committed precursor cells are believed to reside. ${ }^{35}$ Importantly, BMDCs have been shown to consistently express K19 upon recruitment and engraftment in the stomachs of $\mathrm{H}$. felis-infected mice. ${ }^{14}$

In this study, we assessed the ability of bone marrow-derived MSCs to differentiate toward a gastric epithelial cell lineage. We addressed the hypothesis that K19 expression could be used to identify a subset of MSCs that possess the ability to contribute to gastric epithelial cells. Our results suggest that K19-expressing MSCs are absent from the normal bone marrow but are induced by culture conditions in vitro, and in response to $H$. felis infection in vivo. Thus, K19-expressing MSCs possess plasticity along a gastric epithelial lineage and may potentially have a role in healing and repair of the gastric epithelium.

\section{MATERIALS AND METHODS}

Mice

All mice studies and breeding were carried out under the approval of IACUC of Columbia University. Ninety-eight mice were used in this study; 75 of them, including C57BL/6 wild type (WT) mice (8-10 weeks old) and chicken $\beta$-actinenhanced green fluorescent protein (EGFP) transgenic mice (8-10 weeks old), were purchased from Jackson Laboratories (Bar Harbor, ME, USA). Twenty-three study mice were chimeric mice derived from blastocyst injection (Supplementary Table 1).

\section{Isolation and Culture of MSCs}

Bone marrow cells were collected by flushing femurs and tibias with Hank's balanced salt solution (HBSS) and plated at a density of $10^{6} \mathrm{cells} / \mathrm{cm}^{2}$ in murine mesenchymal medium with murine mesenchymal supplements (MesenCult, Stem Cell Technologies, Vancouver, BC, Canada). MSC cultures were derived from five WT mice and five chicken $\beta$-actin EGFP transgenic mice, and maintained individually. Nonadherent cells were removed after $24 \mathrm{~h}$, and culture media were replaced every 5 days. The cells became confluent within $2-3$ weeks at $37^{\circ} \mathrm{C}$ in humid air containing $5 \% \mathrm{CO}_{2}$. Adherent cells were detached by $0.25 \%$ trypsin and $0.02 \%$ ethylene diaminetetraacetic acid (EDTA) at $37^{\circ} \mathrm{C}$ for $2 \mathrm{~min}$ and subsequently passaged in the ratio of $1: 3$ to achieve the required number. The cells of fifth to tenth passage were used for the following protocols.

\section{Colony-Forming Units: Fibroblast Assay}

MSCs were plated at a density of $5 \times 10^{5}$ cells per $\mathrm{cm}^{2}$ and maintained as described above. At day 14, the medium was removed from the wells, washed twice with phosphate-buffered saline (PBS) and fixed/stained with 3\% Crystal violet in $100 \%$ methanol for $10 \mathrm{~min}$ at room temperature. Cells were washed with PBS and colonies were then counted.

\section{Differentiation Assays}

To induce adipocyte differentiation, the subconfluent cells were cultured with MesenCult Stem Cell Medium containing $5.0 \mu \mathrm{g} / \mathrm{ml}$ insulin, $50 \mu \mathrm{M}$ indomethacin, $1 \mu \mathrm{M}$ dexamethasone and $0.5 \mu \mathrm{M}$ 3-Isobutyl-1-methylxanthine. After 14 days, these cells were fixed with $4 \%$ paraformaldehyde for $15 \mathrm{~min}$, and stained with Oil Red-O.

To induce osteocyte differentiation, the subconfluent cells were cultured with MesenCult Stem Cell Medium containing $1 \mathrm{nM}$ dexamethasone, $20 \mathrm{mM} \beta$-glycerolphosphate, $50 \mu \mathrm{M}$ L-ascorbic acid 2-phosphate sesquimagnesium salt, and $50 \mathrm{ng} / \mathrm{ml} \mathrm{L}$-thyroxine sodium pentahydrate. After 14 days, these cells were fixed with $4 \%$ paraformaldehyde for $15 \mathrm{~min}$, and characterization was performed by Alizarin Red staining, which detects calcium deposition.

\section{Induction of Expression of Gastric Phenotype Markers In Vitro}

A total of five stomachs from WT mice (three male and two female mice), aged 8-12 weeks, were used for gastric tissue extract. For each experiment, gastric tissue extract from one stomach was used. The paste from one stomach, made by mortar and pestle, was mixed with $10 \mathrm{ml}$ of MesenCult Stem Cell Medium and incubated at $4{ }^{\circ} \mathrm{C}$ for $24 \mathrm{~h}$. The mixture was centrifuged at 6000 r.p.m. for $20 \mathrm{~min}$, and the supernatant was obtained and filtered using a $0.2 \mu \mathrm{m}$ membrane filter. MSCs were cultured with medium containing gastric extract for 5 days at $37^{\circ} \mathrm{C}$ in humid air containing $5 \% \mathrm{CO}_{2}$. Phenotype markers were detected by real time-PCR (RT-PCR); all primer sequences can be found in Supplementary Table 2 . 


\section{Establishment of K19GFP Vector and Stable Transfection}

cDNAs encoding the mouse K19 promoter sequence and EGFP gene were cloned by PCR from K19- $\beta$ Gal vector (Brembeck FH 2001) and pEGFP N1 vector (Clontech, Mountain View, CA, USA), respectively. They were subcloned into a pcDNA3.1 plasmid (Invitrogen) in which a neomycin selectable marker was encoded. After sequencing, the DNA plasmids were transfected into MSCs with lipofectamine 2000 (Invitrogen) according to a standard protocol (Lipofectamine $10 \mu \mathrm{l}$ per vector DNA $4 \mu \mathrm{g}$ ). Then cells were cultured with MesenCult Stem Cell Medium containing $150 \mathrm{mg} /$ $\mathrm{ml}$ of G418. Colonies were chosen 7 days after transfection and then cultured. $\mathrm{GFP}^{+}$clones were selected under fluorescence microscopy and the expression of GFP was confirmed by flow cytometry. We used the subclones within five passages after establishment for all experiments and confirmed the expression of GFP and K19 in every passage by flow cytometry and RT-PCR, respectively.

\section{Gastric Wall ('Submucosal') Injection of MSCs}

Subconfluent MSCs were removed from the culture plates by treatment with $0.25 \%$ trypsin/EDTA solution and the cells were then treated with MesenCult Stem Cell Medium to stop the reaction. The cells were washed once with PBS and a cell suspension (10000000 cells per $1 \mathrm{ml}$ PBS) was prepared. Four-week-old WT mice were anesthetized with inhalation of isoflurane, the center of the upper abdomen was opened by a $1 \mathrm{~cm}$ incision, and the stomach was lifted outside the abdomen. About $10 \mu \mathrm{l}$ of the cell suspension was injected into each of several points of gastric wall by using a fine glass needle. The abdominal wall was closed by a 5-0 polypropylene surgical suture. Gastric tissue sections were prepared from mice at 2 weeks after injection to detect GFP-positive cells.

\section{Blastocyst Injection of MSCs}

Blastocyst injections were performed in the Transgenic Core Facility of Columbia University Medical School. Three and half day-old blastocysts were extracted from the uteri of WT pregnant females, injected with 10-15 GFP-labeled MSCs and implanted in uteri of Swiss Webster pseudopregnant females. Pups were euthanized at 8 weeks of age and histological or PCR analyses were conducted on stomachs and other organs to detect GFP-labeled cells.

\section{Bone Marrow Transplantation and H. Felis Infection}

Bone marrow transplantation and $H$. felis infection were carried out as previously described. ${ }^{17}$ Briefly, 35 WT female recipient mice received lethal irradiation ( $950 \mathrm{cGy}$ ) from a Cs137 source and after 3 hours, donor whole bone marrow cells ( 5 million cells in $200 \mu \mathrm{l}$ ) were infused via the tail vein. Whole bone marrow cells were prepared from chicken $\beta$-actin EGFP transgenic donor mice, as described above. Five of the recipients did not receive donor bone marrow cell infusion and served as additional controls. Fifteen of the study mice (aged 3 months) received inoculation of $H$. felis by oral gavage, whereas the other 15 recipients remained uninfected. H. felis (ATCC 49179) was used for oral inoculation as described previously. ${ }^{14}$ The organism was grown for $48 \mathrm{~h}$ at $37^{\circ} \mathrm{C}$ under microaerobic conditions on $5 \%$ lysed horse blood agar. Bacteria were harvested and inoculated (at a titer of $10^{10}$ organisms per ml) into brain heart infusion broth with $30 \%$ glycerol added. The bacterial suspension was frozen at $-70^{\circ} \mathrm{C}$. Before use, aliquots were thawed, analyzed for motility, and cultured for evidence of aerobic or anaerobic bacterial contamination. The inocula $(0.5 \mathrm{ml})$ were delivered by gastric intubation into each test mouse three times at 2-day intervals using a sterile oral catheter. ${ }^{59}$ After 1 year of infection, mice were euthanized and both bone marrow and peripheral blood were extracted and used for MSC culture and mRNA detection.

\section{RESULTS \\ Establishment of Bone Marrow-Derived MSC Cultures and Induction of Gastric Phenotype Markers Following Treatment with Gastric Tissue Extract}

We established MSC cultures from whole bone marrow of mice based on their ability to adhere to plastic tissue culture dishes, as previously described. ${ }^{19-23}$ Non-adherent cells were removed, and the primary cultured MSCs became confluent within 2-3 weeks. They grew exponentially for more than 15 passages without signs of senescence or differentiation. After five passages, the pooled MSCs displayed the abilities of colony formation (Figure 1a) and differentiation into both adipocyte and osteocyte lineages under previously defined conditions (Figure 1b). Flow cytometric analysis of these primary MSC cultures revealed that the majority of the cells expressed Scal (94.4\%), but not CD45, c-kit, or Flk1 (Figure 1c).

As recent reports have suggested that a subpopulation of cultured MSCs exhibit multipotency in association with expression of embryonic stem cell markers, ${ }^{29,30}$ we examined the expression of Nanog and Oct-3/4. Low levels of Nanog, but not Oct 3/4, expression were detected in our cultured MSCs (Supplementary Figure S1). Following treatment with gastric tissue extracts (see Materials and Methods), the cultured MSCs altered their morphology from spindle-like fibroblastic to oblong or irregular appearance under phase contrast microscopy (Figure 1d). In addition, treatment of MSCs with gastric extract resulted in increased expression of gastric epithelial phenotypic markers, such as K19, TFF2, MUC5AC, MUC6, H/K-ATPase, and chromogranin A (Figure 1e). These markers represent distinct epithelial cell lineages in the gastric glands (Supplementary Figure S2), suggesting that MSCs may be able to differentiate into any or all lineages. There was no difference in the induction of gastric phenotypic markers using gastric tissue extract prepared from male or female mice (data not shown). 
a

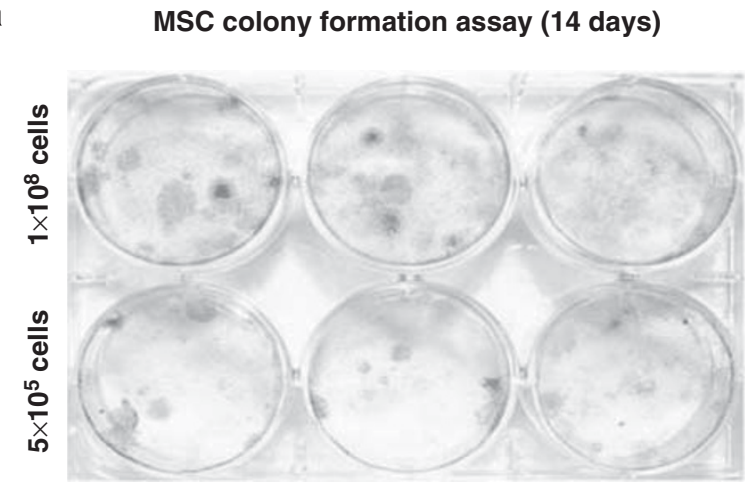

b

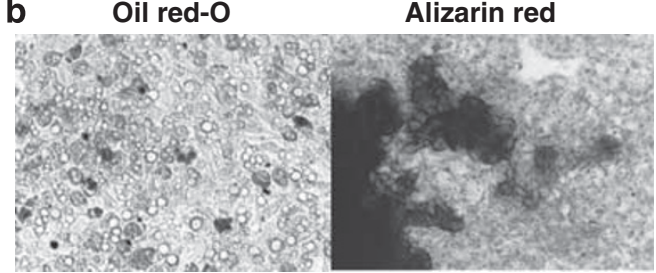

d Gastric Extract (-)

Gastric Extract (+)

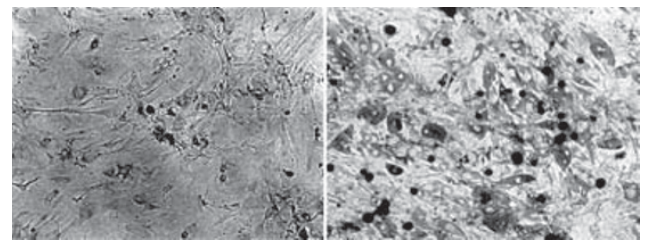

C
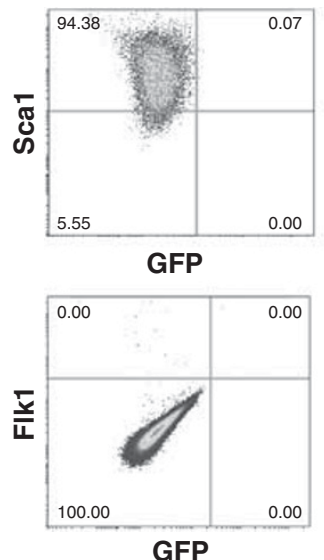
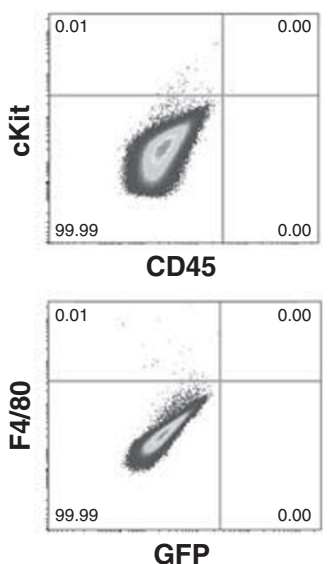

e

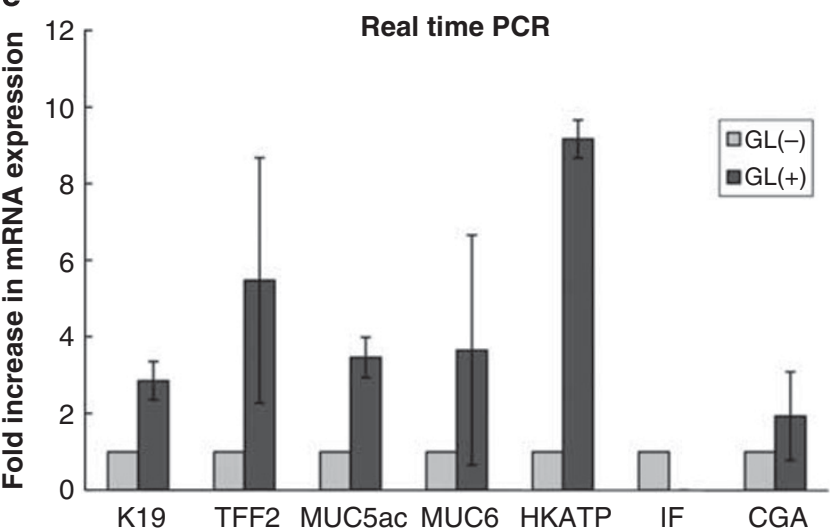

Figure 1 Establishment of bone marrow-derived MSC culture and induced expression of gastric phenotype markers after treatment with gastric tissue extract. (a) Colony formation of MSCs. 500000 or 1000000 cells of MSC at passage 5-10 were seeded onto 6-well tissue culture plate and colonies were visualized with crystal violet staining 14 days after plating. (b) Adipocyte and osteocyte differentiation of MSCs. All established MSC cultures were incubated with adipocyte or osteocyte differentiation medium for 14 days and cells were stained with Oil red-O and Alizarin Red, respectively. (c) Expression of cell surface markers (Sca1, c-kit, CD45, Flk1, and F4/80) was analyzed by flow cytometry. Quadrant markers were set according to the profile of corresponding control lgG staining. Representative examples of three experiments. (d) Morphology of MSCs 5 days after treatment with gastric tissue extract. (e) Expression of gastric epithelial phenotype markers in MSCs after treatment with gastric tissue extract. MSCs were incubated with gastric tissue extract (GL) for 5 days and the mRNA expression of K19, TFF2, Muc5as, Muc6, H/K-ATPase, intrinsic factor (IF), and chromogranin A (CGA) were detected by real-time PCR. Fold increase in mRNA expression (light grey bar) was shown as compared with control cells, which were incubated with culture medium without gastric tissue extract (dark grey bar) was calculated $(n=3)$.

\section{Identification and Isolation of Specific MSC Clones that Express Cytokeratin 19}

We found that K19 was expressed at a low level in most cultured MSCs although a small number of MSCs from select colonies retained high expression, as confirmed by immunocytochemical staining (Figure 2a). Individual MSC colonies were isolated from primary cultures, expanded, and then tested for K19 expression by RT-PCR. High levels of K19 mRNA expression could be detected in approximately one out of 13 subclones derived from a single mouse (Figure $2 \mathrm{~b}$ ). This implied that although K19 expression was present and detectable in a small subset of MSCs, $\mathrm{K}^{+}{ }^{+}$cells could clonally expand and be enriched for K19 expression. Most of these subclones, including the clone with the highest K19 expression, retained the ability to differentiate into osteoblast and adipocyte lineages under appropriate culture conditions (Figure 2c).
To isolate the small number of MSC clones that express K19, primary cultured MSCs were transfected with a K19-EGFP expression vector and stable clones were selected following G418 treatment. Fluorescence microscopy revealed that 3 of 11 isolated clones from the same parent MSCs were positive for GFP expression (Figure 3a) and these clones (K19GFPMSC) were designated K19GFPMSC no. 3, no. 4, and no. 5. Flow cytometry revealed that the percentage of GFP-positive cells was 10.0, 96.2, and $78.6 \%$ for K19GFPMSC no. 3, no. 4, and no. 5, respectively (Figure 3b). Real-time PCR analysis revealed 40- and 35-fold increases in K19 mRNA expression in K19GFPMSC no. 4 and no. 5, respectively, compared with the parent MSCs (Figure 3c). The average K19 mRNA expression of K19GFPMSC no. 3 was increased approximately 42-fold (Figure 3c) when compared with the parental MSCs, and the average K19 
a

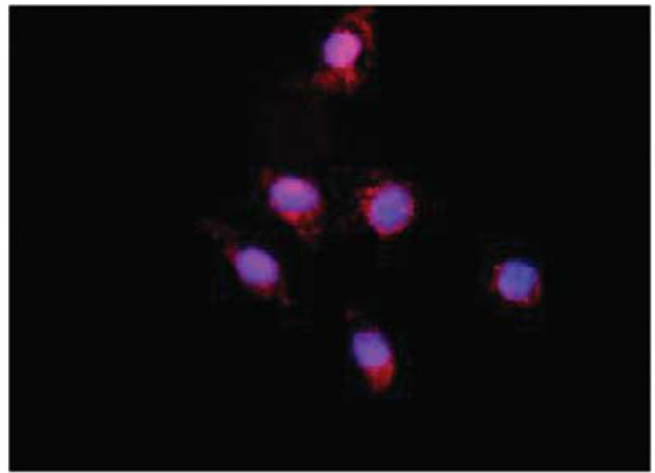

b

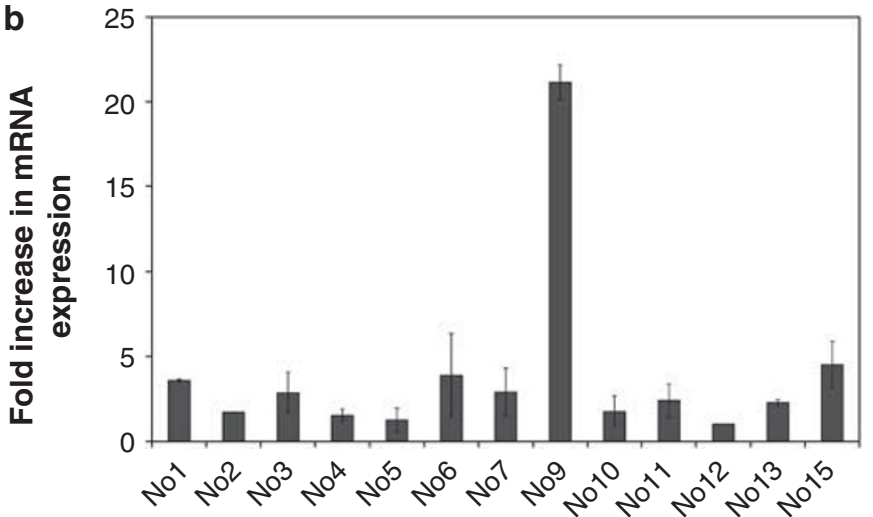

C

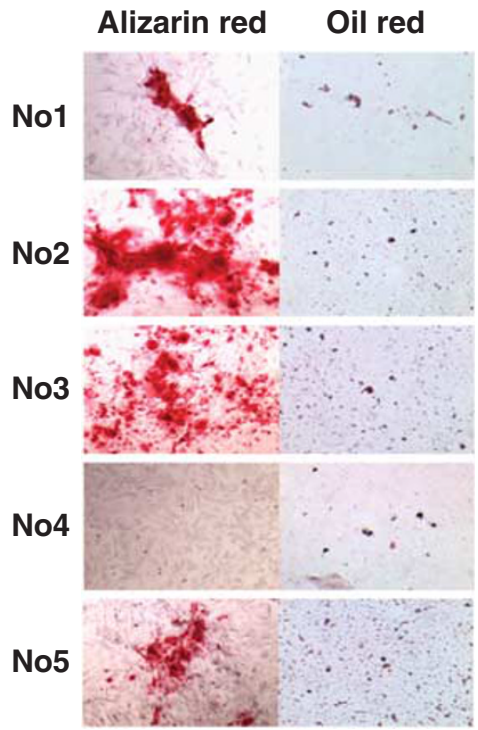

Alizarin red

Oil red

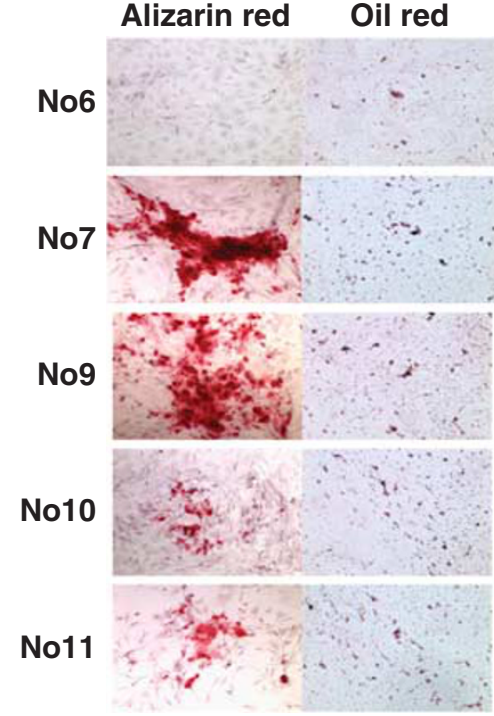

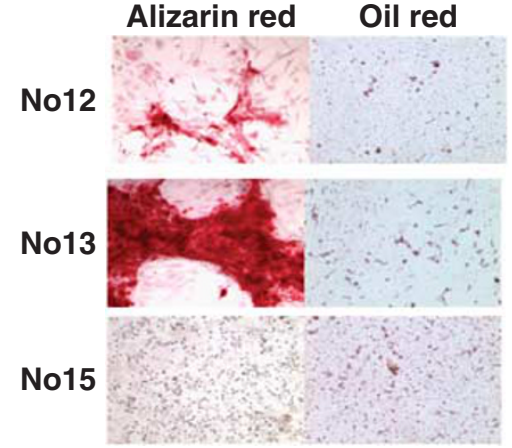

Figure 2 Identification of specific MSC clones that express the epithelial cytokeratin, K19. (a) K19 expression was detected in MSC culture by immunofluorescence with a Texas Red-conjugated anti-K19 antibody. Nuclei were stained with DAPI. Original magnification, $\times 400$. (b) Expression level of K19 mRNA in each MSC clone was quantified by real-time PCR. Fold increase in each clone is shown, as compared to the average expression level of all clones. ( $n=3$ in each clone). (c) Alizarin Red and Oil red-O staining was performed to detect osteoblast and adipocyte differentiation, respectively, in 15 (no. 1 to no. 15) individual MSC clones isolated from the bone marrow of a single mouse, 14 days after treatment with appropriate differentiation medium.

expression in clone no. 3 did not show a statistical difference from the other two clones despite the lower percentage of $\mathrm{GFP}^{+}$cells. K19 mRNA expression in K19GFPMSC no. 3 was primarily due to the high level of K19 expression in the $\mathrm{GFP}^{+}$fraction, with the $\mathrm{GFP}^{+}$cells having a 66 -fold increase in expression compared with 16 -fold for the $\mathrm{GFP}^{-}$cells (Figure 4d). Expression of K19 protein in the three stable MSC clones was confirmed by immunofluorescent staining (Figure 3d). Flow cytometric analysis revealed that expression of a variety of cell surface markers (including Sca-1, CD45, c-kit, Flk1, and F4/80) in the K19GFPMSC clones were roughly similar to that in the parent MSCs (Figure 3b, see also Figure 1c). Although all three K19GFPMSC clones did not express Oct3/4 (Supplementary Figure S1), they did express Nanog and retained the ability to differentiate into adipocyte and osteocyte lineages in culture (Figure 3e).

\section{Treatment with Gastric Tissue Extract Upregulates Expression of Gastric Phenotypic Markers in K19-positive MSCs}

Similar to what had been observed in the parental MSCs, after 5 days of treatment with gastric tissue extract, K19GFPMSCs altered their morphology from spindle-like to oblong or irregular shape (Figure 4a). In addition, the K19GFPMSC clones had significant increases in mRNA expression of gastric phenotypic markers, with up to 60-, 300-, and 170-fold increases in K19GFPMSC clones no. 3, no. 4, and no. 5, respectively. In contrast, less than 10-fold increases were observed in the parental MSCs and mock transfectants (Figure 4b). Although the induced gastric phenotype mRNA expression in K19GFPMSCs treated with gastric tissue extract was much lower than that seen in gastric tissues, this observation was reproducible in at least three separate experiments (Supplementary Figure S3). In contrast, 

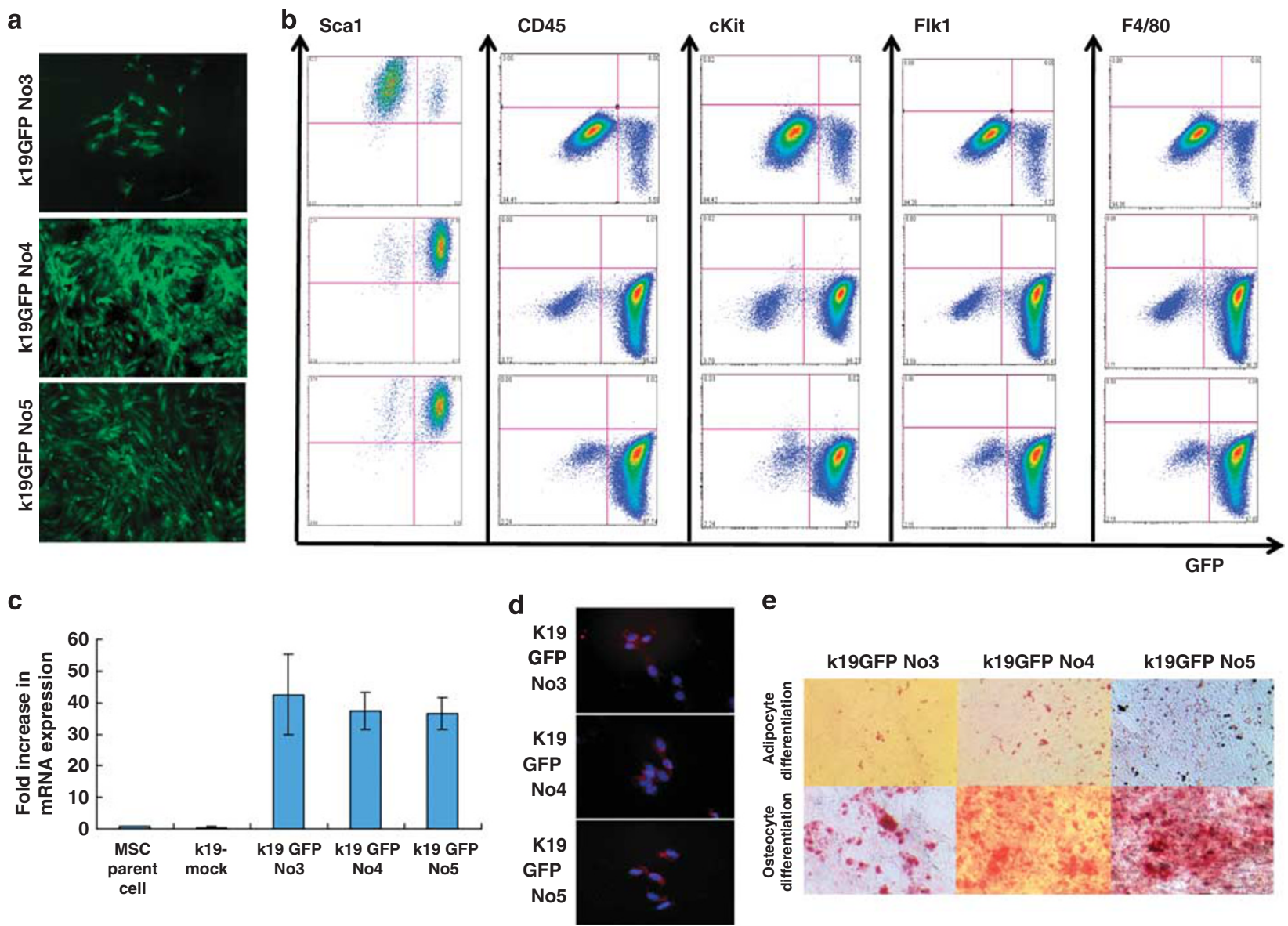

e

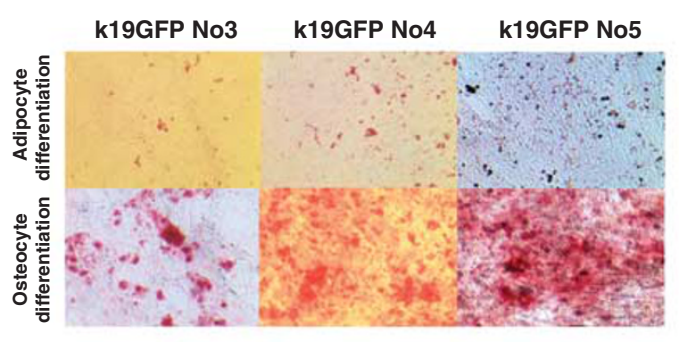

Figure 3 Establishment of GFP-labeled MSC clones, that express K19. (a) GFP expression in MSC clones established by transfection with a K19-EGFP gene construct. After selection with G418 treatment, 3 of 11 isolated clones expressed GFP and were designated as K19GFP no. 3, no. 4, and no. 5. (b) Expression of GFP and cell surface markers (Sca1, c-kit, CD45, Flk1, and F4/80) in GFP-positive clones was analyzed by flow cytometry. Cells were stained with PEconjugated antibodies, and both antibody staining and endogenous GFP expression was detected. Quadrant markers were set according to the profile of control lgG staining in GFP-negative parent cells. Representative examples of three experiments are shown. (c) Fold increase in K19 mRNA expression level in mock transfectant, K19GFP no. 3, no. 4, and no. 5 is shown, as compared with that of parent cells by RT-PCR $(n=3)$. (d) K19 protein expression in GFPpositive clones was assessed by immunofluorescence staining with a Texas Red conjugated anti-K19 antibody. Nuclei were stained with DAPI. Original magnification, $\times 100$. (e) Osteocyte and adipocyte differentiation 14 days after incubation with appropriate culture condition in K19GFP no. 3, no. 4, and no. 5 were detected by Alizarin Red and Oil red-O staining, respectively. Original magnification, $\times 40$.

stimulation of MSCs with colonic or pancreatic tissue extract did not induce expression of gastric phenotype markers, although the treatments modestly increased expression of genes associated with their respective tissues (Supplementary Figure S4c).

\section{Progenitor-like Characteristics of K19GFP ${ }^{+}$MSCs}

After twenty-eight days of culture, sorted $\mathrm{GFP}^{+}$cells from K19GFPMSC no. 3 gave rise to both $\mathrm{GFP}^{+}$and $\mathrm{GFP}^{-}$cells, whereas $\mathrm{GFP}^{-}$cells never gave rise to $\mathrm{GFP}^{+}$cells under the same conditions (Figure 4c). BrdU assays showed that $\mathrm{GFP}^{+}$ cells exhibit higher proliferation rates than $\mathrm{GFP}^{-}$MSCs (eight samples each, unpaired Student's $t$-test $P=0.0029$ ) (Figure 4f). RT-PCR revealed a higher basal level of K19 mRNA expression in $\mathrm{GFP}^{+}$MSCs compared with $\mathrm{GFP}^{-}$MSCs (Figure 4d). Following treatment with gastric tissue extract, the K19-expressing $\mathrm{GFP}^{+}$fraction showed greater upregulation of gastric phenotypic markers, such as TFF2 and
$\mathrm{H} / \mathrm{K}$-ATPase, compared with the $\mathrm{GFP}^{-}$fraction (Figure 4e). Single cell sorting (Figure $4 \mathrm{~g}$ ) revealed that K19GFP no. 3 cells could divide and generate colonies (Figure 4h). Fourteen days after plating, there were $5.3 \pm 2.5$ and $13.6 \pm 3.5$ colonies $(P=0.029)$ from $\mathrm{GFP}^{-}$and $\mathrm{GFP}^{+}$cell fractions, respectively $(n=3)$. After treatment with gastric tissue extract, the overall pattern of gastric phenotype marker expression was similar between colonies from the single-sorted and pooled $\mathrm{GFP}^{+}$and $\mathrm{GFP}^{-}$MSCs (Figure 4i). Accordingly, the difference between $\mathrm{GFP}^{+}$and $\mathrm{GFP}^{-}$ MSCs remained significant in the analysis of colonies from single sorted clones. In addition, isolation of single colonies from $\mathrm{GFP}^{+}$MSCs treated with gastric extract exhibited the same pattern of gene expression when re-incubated with gastric extract (data not shown). Taken together, these data show that 10\% of K19GFPMSC no. 3 were $\mathrm{GFP}^{+}$and expressed the highest K19 levels and had a greater potential to upregulate certain gastric phenotypic 

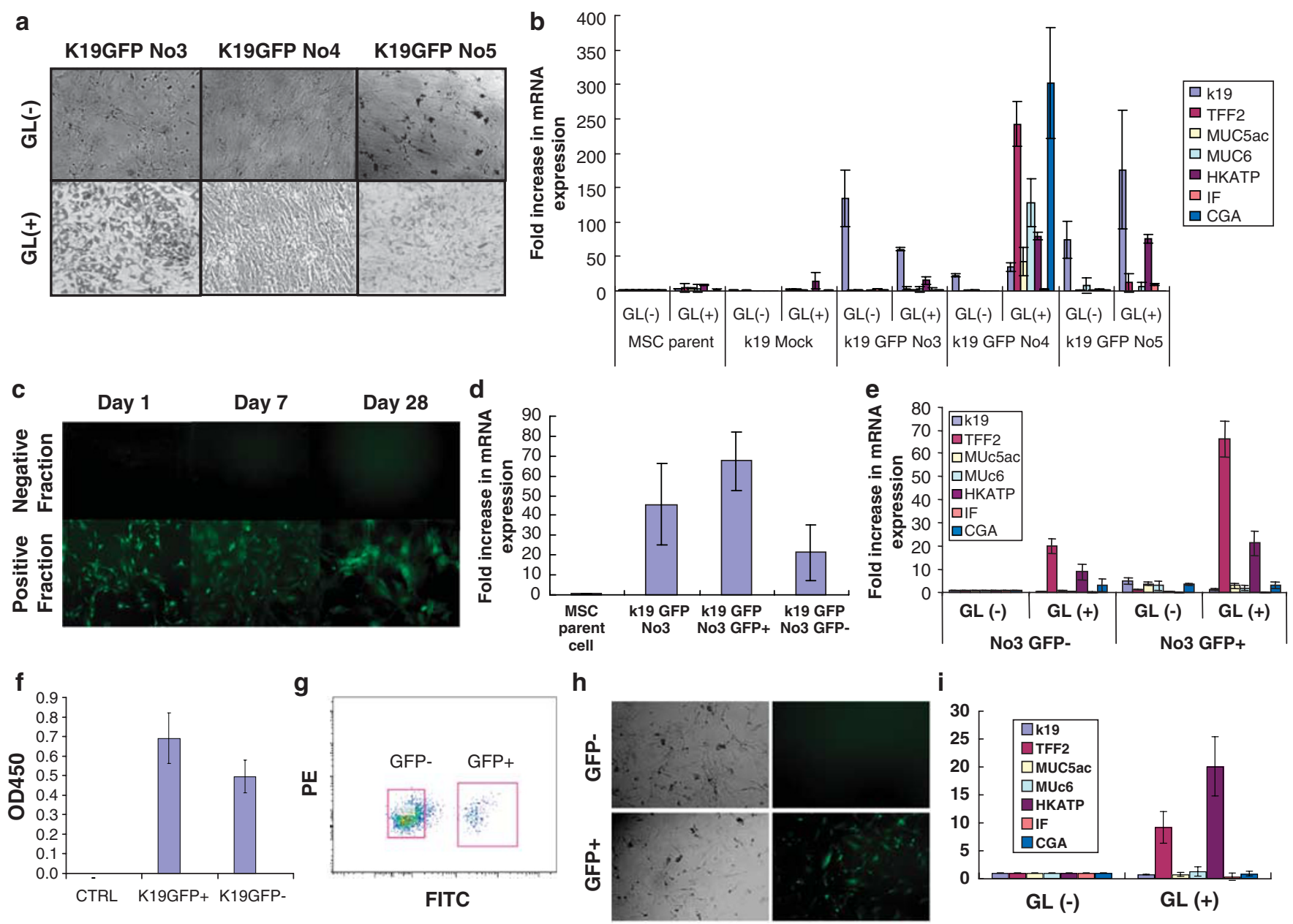

Figure 4 Induced expression of gastric phenotype markers in K19-positive MSC clones after treatment with gastric tissue extract. (a) K19GFP MSC clone no. 3, no. 4, and no. 5 were incubated with gastric tissue extract (GL) for 5 days. The morphology of K19GFP MSC clones no. 3, no. 4, and no. 5 after treatment is shown. Original magnification, $\times 100$. (b) Expression of gastric epithelial phenotype markers, such as k19, TFF2, Muc5ac, Muc6, H/K-ATPase, IF, and CGA in K19GFP MSC clones after treatment with GL assessed by real-time PCR. Average data of three separate experiments is shown. (c) Sorted GFP ${ }^{+}$and GFP ${ }^{-}$ cells of K19GFPMSCNo3 were cultured separately, and the expression of GFP was assessed after 1, 7, and 28 days of culture. GFP ${ }^{-}$cells could not generate $\mathrm{GFP}^{+}$cells. Original magnification, $\times 100$. (d) Fold increase in K19 mRNA expression level in pooled K19GFP No3, sorted GFP ${ }^{+}$and GFP fraction were compared with that of parent cells by real-time PCR. $(n=3)$. (e) The expression of gastric epithelial phenotypic markers, such as K19, TFF2, Muc5ac, Muc6, $\mathrm{H} / \mathrm{K}$-ATPase, IF, and CGA in the sorted GFP ${ }^{+}$and $\mathrm{GFP}^{-}$cells after treatment with GL were assessed by real-time PCR. (f) BrdU assay using K19GFP MSC clone no. 3 revealed a higher proliferation ability of GFP ${ }^{+}$MSCs over GFP $^{-}$MSCs (eight samples each, unpaired Student's $t$-test $P=0.0029$ ). (g) GFP ${ }^{+}$and GFP ${ }^{-}$ cells were isolated by fluorescent cell sorting from K19GFP no. 3. (h) Colony-forming ability of single-sorted GFP ${ }^{+}$and GFP cells isolated from K19GFP MSC clone no. $3 . \mathrm{GFP}^{+}$cells could give rise to both $\mathrm{GFP}^{+}$and $\mathrm{GFP}^{-}$cells, whereas GFP ${ }^{-}$cells could not generate GFP ${ }^{+}$cells. Original magnification, $\times 100$. (i) The expression of gastric epithelial phenotypic markers, such as K19, TFF2, Muc5ac, Muc6, H/K-ATPase, IF, and CGA in the colonies derived from singlesorted $\mathrm{GFP}^{+}$and $\mathrm{GFP}^{-}$cells after treatment with GL were assessed by RT-PCR.

markers without specifying a particular differentiated gastric epithelial lineage. The results suggest that the MSCs with higher K19 expression may represent a progenitor cell fraction.

\section{In Vivo Differentiation of K19-positive MSCs into Gastric Epithelial Cells}

To test the differentiation ability of MSCs in adult animals, two hundred thousand $(200000)$ cells from either K19GFPMSC no. 4 or control MSCs obtained from the bone marrow of chicken $\beta$-actin EGFP transgenic mice (GFPMSC), were injected directly into the stomach wall of
WT-mice (Supplementary Figure S5, see also Figure 1c). Twenty-four hours after injection of control GFPMSC cells, $\mathrm{GFP}^{+}$cells were distributed in the mucosa, submucosa, and subserosa of the stomach (Supplementary Figure S6). A similar pattern was observed for the K19GFPMSC cells. Two weeks after injection of K19GFPMSC no. 4, GFP ${ }^{+}$cells could be detected scattered throughout the gastric epithelium, with many showing expression of the epithelial-specific marker, E-cadherin (Figure 5a). Stomach sections from mice injected 2 weeks earlier with the control GFPMSCs had fewer total GFP cells, but some were also positive for E-cadherin in the gastric epithelium (Figure 5b). 
In females receiving an injection of male MSCs, we performed Y chromosome FISH to detect any MSC-derived cells that did not express GFP due to silenced chicken $\beta$-actin/k19 promoter activity. However, we found a similar number of Y chromosome-positive cells scattered throughout the epithelium, suggesting that this procedure offered little advantage over GFP detection (data not shown). We also injected K19GFPMSC no. 4 and GFPMSC into gastric walls of WT mice with long-term (12 months) $\mathrm{H}$. felis infection to investigate whether a chronic inflammatory environment wound enhances the engraftment of MSC. However, there was no significant increase in the number of engrafted GFP-positive cells in the gastric epithelium (data not shown).

To test the differentiation ability of these cells under embryonic conditions, we performed blastocyst injections of GFP-labeled MSCs. Following blastocyst injection of control GFPMSCs, the GFP DNA sequence was detected by PCR in tail DNA from 6 of 10 chimeric offspring (Supplementary Figure S7A), and analysis of gastric sections from 8-week-old mice showed GFP ${ }^{+}$cells in the gastric epithelium in 3 of 10 animals (Supplementary Figure S7B). Some of the GFP ${ }^{+}$ gastric cells also stained E-cadherin positive (Figure $5 \mathrm{c}$ ). In comparison, $\mathrm{GFP}^{+}$cells could be detected in the gastric
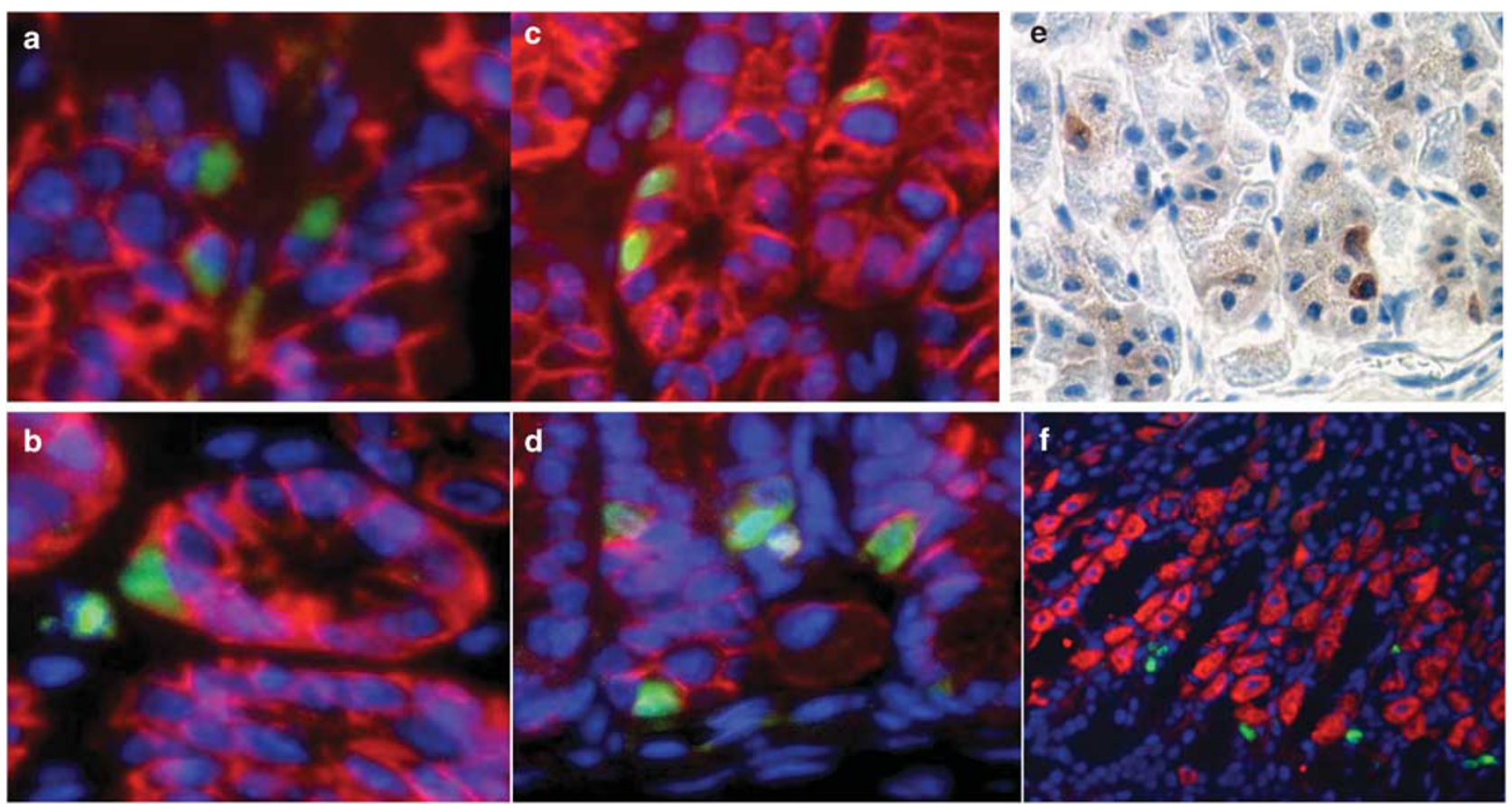

\begin{tabular}{|l|c|c|c|c|}
\hline & \multicolumn{2}{|c|}{ Gastric Wall Injection } & \multicolumn{2}{c|}{ Blastocyst Injection } \\
\cline { 2 - 5 } & GFP MSC & K19 MSC & GFP MSC & K19 MSC \\
\hline GFP detection (pups) & $10 / 10$ & $10 / 10$ & $3 / 10$ & $13 / 13$ \\
\hline Ave. GFP(+) cells/ HPF & $10.2+/-2.7$ & $35.0+/-6.3$ & $5.0+/-1.4$ & $8.3+/-0.9$ \\
\hline
\end{tabular}

Figure 5 Contribution of K19-positive MSCs to the gastric epithelium in vivo. (a) GFPMSCs (200 000 cells in $10 \mu$ l of PBS) were injected into the gastric wall of C57BL/6 mice and gastric tissue sections were prepared 2 weeks after injection. Sections were stained with an anti-E-cadherin antibody and Texas Redconjugated secondary antibody. Nuclei were stained with DAPI. Original magnification, $\times 400$. (b) K19GFP MSC no. 4 (200 000 cells in $10 \mu$ l of PBS) were injected into the gastric wall of C57BL/6 mice and gastric tissue sections were prepared 2 weeks after injection. Sections were stained with an antiE-cadherin antibody and Texas Red-conjugated secondary antibody. Original magnification, $\times 400$. (c) GFPMSCs were injected into 3.5 day-old mouse blastocysts to establish chimeric mice and gastric tissue sections were prepared at 8 weeks of age. Sections were stained with an anti-E-cadherin antibody in combination with Texas Red-conjugated secondary antibody. Nuclei were stained with DAPI. Original magnification, $\times 400$. (d) K19GFP MSC no. 4 was injected into 3.5 day-old mouse blastocysts to establish chimeric mice and gastric tissue sections were prepared at 8 weeks of age. Sections were stained with an anti-E-cadherin antibody and Texas Red-conjugated secondary antibody. Nuclei were stained with DAPI. Original magnification, $\times 400$. (e) Immunohistochemistry with an anti-GFP antibody. Representative stomach section of a mouse derived from blastocyst injection of GFPMSC is shown. Original magnification, $\times 300$. (f) Immunofluorescence of H/K-ATPase and GFP-positive cells. Sections were stained with an anti H/K-ATPase antibody and Texas Red-conjugated secondary antibody. Nuclei were stained with DAPI. A representative stomach section of a mouse derived from blastocyst injection of GFPMSC is shown. Original magnification, $\times 200$. (g) $\mathrm{GFP}^{+}$cell detection rate and GFP ${ }^{+}$cells per high-power field (HPF) in both gastric wall injection and blastocyst injection studies. 
epithelium of all 13 pups derived from blastocyst injections of K19GFPMSC no. 4, (Supplementary Figure S7C and S7D) with many $\mathrm{GFP}^{+}$E-cadherin ${ }^{+}$cells distributed throughout the gastric epithelium (Figure 5d). We confirmed the localization of GFP inside and E-cadherin on the membrane of the same cells under confocal microscopy (Supplementary Figure S8). Anti-GFP immunohistochemistry further confirmed engraftment of injected MSCs into the gastric mucosa (Figure 5e). To track the differentiation of these engrafted MSCs, we performed immunohistochemistry for $\mathrm{H} / \mathrm{K}$-ATPase, intrinsic factor, chromogranin A, MUC5AC and MUC6, although we did not find any $\mathrm{GFP}^{+}$cells coexpressing these markers in any of the sections (Figure 5f). The GFP detection rate, based on the number of animals positive for GFP expression and the number of $\mathrm{GFP}^{+}$cells per high-power field (HPF) (average of $10 \mathrm{HPFs}$ ), from both the gastric wall injection study and the blastocyst injection study, are summarized in Figure 5g. Overall, it appeared that K19GFPMSCs had an engraftment rate equal to or greater than that of pooled GFPMSCs. We performed flow-cytometric analysis of bone marrow from chimera mice derived from blastocyst injections, and found a very small number of $\mathrm{GFP}^{+}$cells in only a few mice. Gastric epithelial engraftment was seen in mice both with and without bone marrow engraftment, indicating that blastocyst-injected MSC's were capable of primarily engrafting into the foregut endoderm, rather than engrafting into the adult gastric epithelium following initial engraftment in the bone marrow. $\mathrm{GFP}^{+}$cells were also detected in stromal areas of the epidermis of these mice (Supplementary Figure S9), indicating that K19GFPMSCs retain the capacity to contribute to stromal lineages.

\section{K19-positive MSCs in Peripheral Blood of Mice with Chronic $\boldsymbol{H}$. felis Infection}

We did not detect expression of K19 mRNA by RT-PCR in fresh bone marrow cells from mice, regardless of whether they had chronic $H$. felis infection (not shown). However, K19 mRNA expression was detected in the mononuclear cell fraction of peripheral blood of mice and was highly upregulated by chronic H. felis infection (Figure 6a). Because there are currently no consensus markers to directly isolate MSCs from peripheral blood, the mononuclear cell fraction of peripheral blood from mice with $H$. felis infection was seeded onto plastic plates with MSC culture medium. Spindle-like fibroblastic cells proliferated exponentially whereas many round-shaped cells did not grow and were lost from the culture after passage (Figure 6b). We designated the spindlelike fibroblastic cells as peripheral blood-derived MSCs (PBMSCs) because they showed adipocyte and osteoblast differentiation under appropriate culture conditions (Figure $6 c)$. PBMSCs were established from 5 of 13 mice $(38.5 \%)$ that were chronically $H$. felis-infected and from only 1 of 14 (7.1\%) age-matched uninfected control mice. Most of the PBMSCs were GFP ${ }^{+}$when they were established from mice that received bone marrow transplants from chicken $\beta$-actin
EGFP donor mice (Figure 6d), suggesting the bone marrow origin of these PBMSCs. In addition, PBMSCs had increased expression of the gastric epithelial phenotypic markers, TFF2 and $\mathrm{H} / \mathrm{K}$-ATPase, after treatment with gastric tissue extract in vitro (Figure 6e), showing a similarity in phenotype with bone marrow-derived cultured MSCs. However, there was no significant difference in the expression of K19 or other markers that were tested.

\section{DISCUSSION}

A number of studies have shown that mesenchymal stem cells possess unexpected plasticity and are able to differentiate across germ layer boundaries to give rise to epithelial tissues. ${ }^{28-30}$ Previous reports by our group suggested MSCs as a possible candidate for the bone marrow-derived progenitor cells that give rise to cytokeratin-positive metaplastic cells in the gastric epithelium during chronic $H$. felis infection. ${ }^{17}$ In vitro studies indicated that MSCs, but not HSCs, could acquire an epithelial morphology and upregulate the expression of epithelial markers such as cytokeratin 19, when exposed to gastric extract. ${ }^{17}$ In this study, we show that the K19-expressing MSC subclones possess all of the gastric differentiating abilities of MSCs, and can give rise to gastric epithelial cells when injected into the adult mouse stomach or early blastocysts. Finally, K19-expressing MSCs give rise to ${\mathrm{K} 19^{-}}^{-} \mathrm{MSCs}$, and are mobilized into the circulation by chronic $H$. felis infection.

Bone marrow-derived MSCs have been isolated and characterized in the past based on their fibroblast-like morphology, ability to proliferate in vitro, and potential to differentiate into multiple lineages. ${ }^{40-45}$ Nevertheless, no clear consensus regarding the expression of specific cell surface markers has emerged. ${ }^{40-42,46}$ To isolate MSCs in our studies, we cultured whole bone marrow on plastic tissue culture plates with medium containing 10\% serum and passaged the adherent cells more than five times to eliminate contamination by hematopoietic and endothelial fractions. We showed that our MSCs were $\mathrm{CD}_{4} 5^{-}, \mathrm{Flk1} 1^{-}, \mathrm{F} 4 / 80^{-}$by flow cytometry. We confirmed their MSC phenotype by their ability to form colonies in soft agar and differentiation to osteocytes and adipocytes. However, even cultured and enriched MSCs remained morphologically heterogeneous, ${ }^{46}$ and colonies derived from them were diverse in both appearance and differentiation potential. ${ }^{40,46-48}$

Cytokeratin 19 is a marker of early epithelial progenitors, ${ }^{39}$ particularly in the stomach ${ }^{35-38}$ and we noted upregulation of K19 when pooled MSCs were exposed to gastric tissue extract. We investigated K19 expression in individual MSC subclones and found that only a minority of individual clones spontaneously expressed K19 under basal culture conditions. Using a K19-GFP transfection approach, we selected K19-expressing clones and showed that they were generally equivalent to the parental MSCs in terms of their capacity to differentiate into gastric epithelial cells when injected into adult mouse stomachs or early blastocysts. 

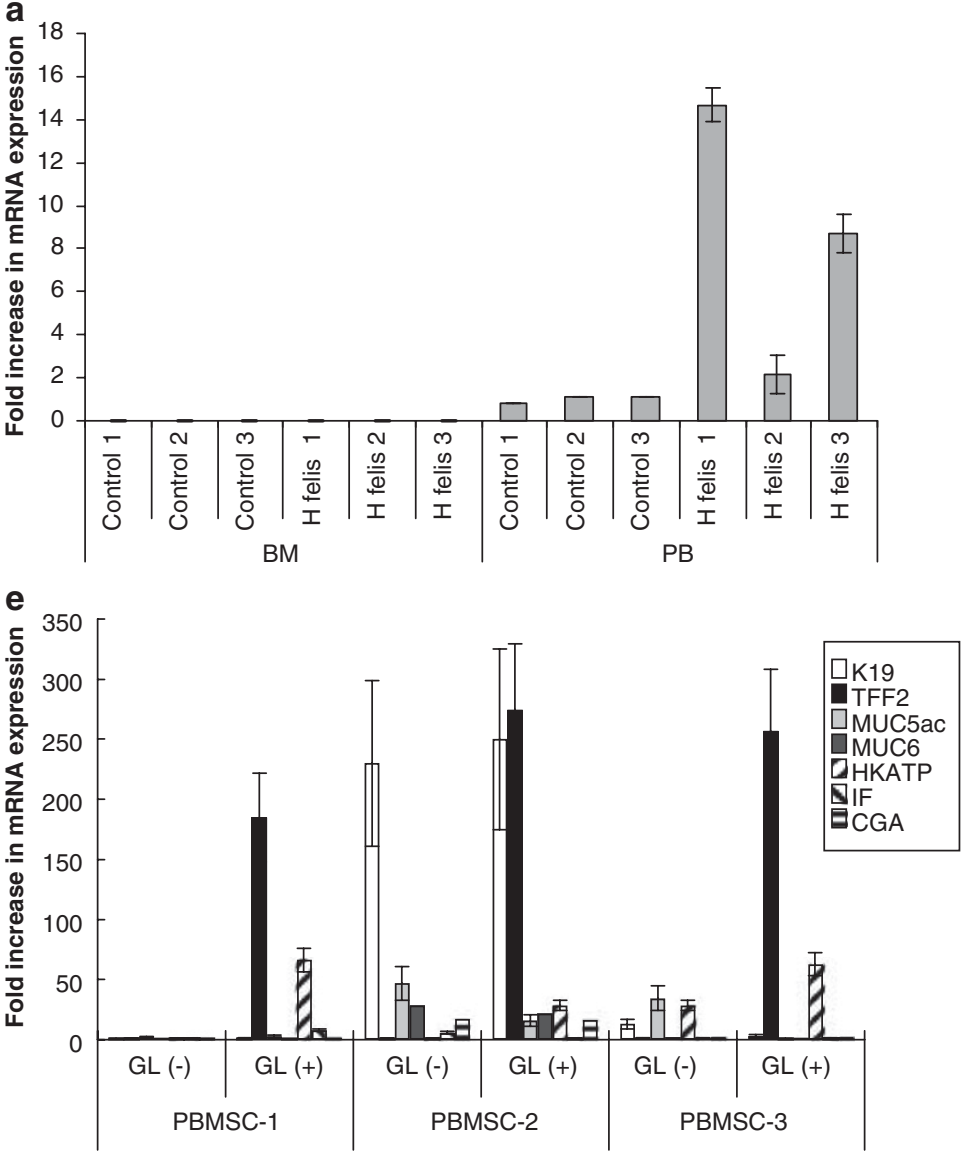

b

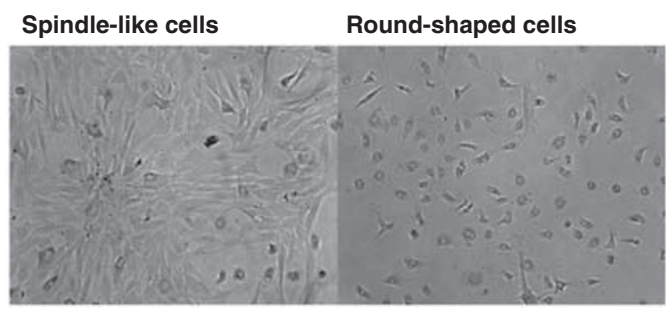

C Oil red-O Alizarin red

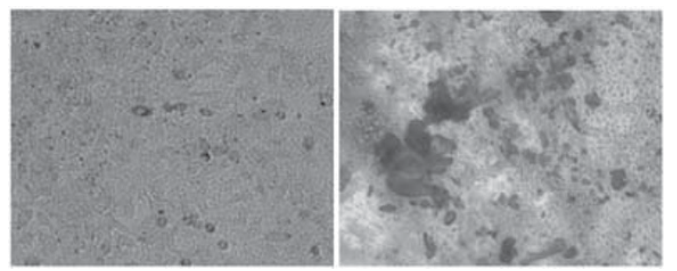

d

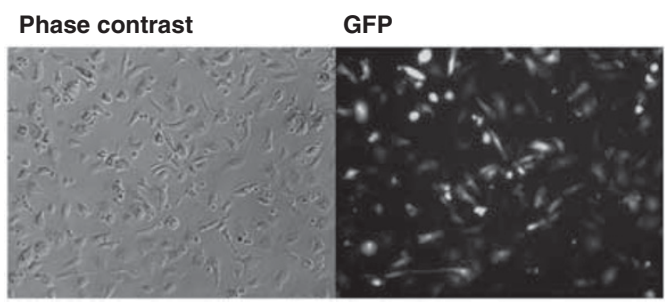

Figure 6 K19-positive MSCs in the peripheral blood of mice with chronic $H$. felis infection. (a) Expression of K19 mRNA in freshly isolated mononuclear cell fraction in bone marrow (BM) or peripheral blood (PB) of mice with or without $H$. felis-associated chronic gastritis. (b) Attached cell fraction 14 days after seeding of peripheral blood from mice with chronic $\mathrm{H}$. felis infection. (c) Adipocyte and osteocyte differentiation of MSC clones established from peripheral blood. PBMSCs were incubated with adipocyte or osteocyte differentiation medium for 14 days and cells were stained with Oil red-O or Alizarin Red, respectively. (d) GFP-positive cells in MSC culture established from peripheral blood of C57/BL6 mice that received bone marrow transplantation from chicken $\beta$-actin EGFP donor mice and subsequent chronic $H$. felis infection. (e) Expression of gastric epithelial phenotype markers in peripheral bloodderived MSC clones after treatment with gastric tissue extract (GL). Cells were incubated with gastric tissue extract for 5 days and the mRNA expression of K19, TFF2, Muc5as, Muc6, H/K-ATPase, IF, and CGA were detected by real-time PCR.

In addition, $\mathrm{K}^{19-\mathrm{GFP}^{+}}$cells gave rise to $\mathrm{GFP}^{-}$cells that possessed limited potential of in vitro differentiation. This indicated that the $\mathrm{K} 19^{+}$cells are the more primitive fraction in the cell line.

Although the K19-GFPMSCs appeared to possess some degree of longevity and self-renewal ability, in vivo studies with these passaged cells raise some question as to whether these cells are progenitors rather than true stem cells. In all of the stomach sections in which GFP positivity was detected, positive cells presented as single cells scattering throughout the gastric epithelium. Neither $\mathrm{GFP}^{+}$clonal glands nor $\mathrm{GFP}^{+}$clusters were detected. This is consistent with previous reports that bone marrow-derived cells are detected as single differentiated epithelial cells in the uninjured gastrointestinal tract. $^{8,10,30}$ In addition, none of the single, scattered $\mathrm{GFP}^{+}$ cells showed expression of H/K-ATPase, indicating limited ability to differentiate into parietal cells, the most abundant type of differentiated cells in the gastric epithelium. These $\mathrm{GFP}^{+}$gastric epithelial cells also did not express other markers of differentiated gastric epithelial cells, such as intrinsic factor, chromogranin A, MUC5AC or MUC6. A possible explanation for the lack of clonal glands is that MSCs do not engraft into the stem cell niche under normal conditions. However, it is also likely that our MSCs gradually lost their stemness or multipotentiality during culture. Our in vitro studies indicate that even after exposure to gastric extract, they induce expression of multiple gastric genes rather than a single, lineage-defining gene, consistent with a progenitor phenotype. Multipotent mesenchymal stem cells have been reported to exist in the bone marrow, ${ }^{29,30,32,49,50}$ and these cells show expression of ES cell marker genes, such as Oct3/4 and Nanog. ${ }^{29,30}$ In this study, both the parental MSC cultures and the $\mathrm{K} 19^{+}$MSC clones expressed Nanog, but were negative for Oct3/4 and SSEA-1. This suggests that they are not identical with the previously reported multipotent mesenchymal progenitor cells. Finally, it is possible that the injected MSCs undergo cell fusion in vivo, and this could explain the finding of single-scattered $\mathrm{GFP}^{+}$ cells in the stomach. ${ }^{51}$ 
Although K19 mRNA expression was not detectable in the freshly isolated bone marrow mononuclear cell fraction, it was detected in the peripheral blood of mice with chronic H. felis infection. Studies examining K19 expression in both cultured bone marrow- and peripheral circulation-derived MSCs suggest that removal of MSCs from their normal bone marrow niche may in part trigger the upregulation of K19 and the epithelial progenitor program. Furthermore, we were able to grow more MSC cultures from peripheral blood of $H$. felis-infected mice than that from uninfected control mice. Donor-derived MSCs were identified in the peripheral blood of mice having undergone both bone marrow transplantation and chronic infection with $\mathrm{H}$. felis. The presence of MSCs in the peripheral blood, ${ }^{52-54}$ and mobilization of these bone marrow-derived cells into the peripheral circulation under chronic inflammatory states or injury has previously been described. ${ }^{55,56}$ Given that no definitive cell surface markers are currently available to distinguish MSCs from non-MSC cells in mice, we could not completely exclude the possibility that the detected K19-expressing transcripts in peripheral blood are due to phagocytosed cell fragments liberated from the injured gastric epithelium. Nevertheless, taken together, our results suggest that the expression of K19 is induced in bone marrow-derived MSCs after they are recruited into the circulation in response to chronic $H$. felis infection.

Our in vitro study with gastric tissue extracts suggests that K19 expression is induced in MSCs when they are recruited into the gastric tissue environment. However, our finding of K19-expressing MSCs in the peripheral circulation also suggests the possibility that MSCs express K19 upon release from the bone marrow niche and/or after exposure to factors in the blood. These cells may represent epithelial progenitor cells uncommitted to a specific epithelial lineage, possibly induced by systemic factors released from inflamed gastric mucosa, whereas exposure to the gastric environment reinforces K19 expression and represents cells committed to the gastric epithelial lineage. Identification of MSC-specific markers would be necessary to isolate these cells from peripheral blood and determine more precisely their in vivo biology.

We treated cultured MSCs with whole gastric tissue extract based on earlier studies. ${ }^{14}$ There are several possible morphogenetic signals that have been reported to participate in the morphogenesis of gastrointestinal tract, including extracellular matrix interactions, ${ }^{57}$ sonic hedgehog, ${ }^{58}$ transforming growth factor (TGF) $\beta,{ }^{59}$ fibroblast growth factors (FGFs), ${ }^{60}$ epimorphin, ${ }^{61}$ hepatocyte growth factor (HGF), ${ }^{62}$ and bone morphogenetic proteins. ${ }^{63}$ Despite this work, no definitive combination of factors has been shown to successfully induce gastric differentiation in MSCs in vitro. Further investigation of specific components in the gastric extracts used in this study may provide important insights regarding gastric differentiation.

In this study, we found that chicken $\beta$-actin eGFP MSCs (hemizygous, C57BL/6-Tg (ACTB-EGFP) 10sb/J, JAX Stock number: 003291) expressed weak, primarily nuclear
GFP when engrafted as epithelial cells, whereas the GFP in the epithelial cells derived from K19GFPMSC was quite robust. Chicken $\beta$-actin eGFP was previously reported to be poorly expressed in the gastrointestinal tract, ${ }^{64,65}$ and can traffic back into the nucleus following expression in the cytosol. ${ }^{66}$ Nevertheless, epithelial expression of GFP was supported by the observation that GFP and E-cadherin were co-localized under confocal microscopy (Supplementary Figure S7C-S7E).

In conclusion, we report that bone marrow-derived MSCs can contribute to the gastric epithelium in vivo, and that the $\mathrm{K} 19^{+}$MSC subset is most likely responsible for this process. We also report $\mathrm{K}_{19}{ }^{+}$MSC mobilize to the peripheral blood in the setting of chronic $H$. felis infection. Although further studies are necessary to determine whether these MSCs can contribute to carcinogenesis, our data provides support for an MSC subset that could potentially contribute to gastric epithelial regeneration and repair.

Supplementary Information accompanies the paper on the Laboratory Investigation website (http://www.laboratoryinvestigation.org)

\section{ACKNOWLEDGEMENTS}

We thank Dr Victor Lin of the Transgenic Core Facility of Columbia University Medical School for blastocyst injection, Ms. Kelly S. Betz, Dr Melitta Penz, and Ms. Shanisha Gordon for animal care and technical assistances. This work was supported by grants from NIH 5R01 CA120979-02 (TCW), NIH R01 DK060694 (AKR) and The Uehara Memorial Foundation (TO).

\section{DISCLOSURE/CONFLICT OF INTEREST}

The authors state no conflict of interest.

1. Theise ND, Badve S, Saxena R, et al. Derivation of hepatocytes from bone marrow cells in mice after radiation-induced myeloablation. Hepatology 2000;31:235-240.

2. Spencer $H$, Rampling $D$, Aurora $P$, et al. Transbronchial biopsies provide longitudinal evidence for epithelial chimerism in children following sex mismatched lung transplantation. Thorax 2005;60:60-62.

3. Suratt $B T$, Cool $C D$, Serls $A E$, et al. Human pulmonary chimerism after hematopoietic stem cell transplantation. Am J Respir Crit Care Med 2003;168:318-322.

4. Korbling M, Katz RL, Khanna A, et al. Hepatocytes and epithelial cells of donor origin in recipients of peripheral-blood stem cells. N Engl J Med 2002;346:738-746.

5. Okamoto R, Yajima T, Yamazaki $M$, et al. Damaged epithelia regenerated by bone marrow-derived cells in the human gastrointestinal tract. Nat Med 2002;8:1011-1017.

6. Ishikawa F, Yasukawa M, Yoshida S, et al. Human cord blood- and bone marrow-derived CD34+ cells regenerate gastrointestinal epithelial cells. FASEB J 2004;18:1958-1960.

7. Matsumoto T, Okamoto R, Yajima T, et al. Increase of bone marrowderived secretory lineage epithelial cells during regeneration in the human intestine. Gastroenterology 2005;128:1851-1867.

8. Spyridonidis A, Schmitt-Graff A, Tomann T, et al. Epithelial tissue chimerism after human hematopoietic cell transplantation is a real phenomenon. Am J Pathol 2004;164:1147-1155.

9. Petersen $\mathrm{BE}$, Bowen $\mathrm{WC}$, Patrene $\mathrm{KD}$, et al. Bone marrow as a potential source of hepatic oval cells. Science 1999;284:1168-1170.

10. Krause DS, Theise ND, Collector Ml, et al. Multi-organ, multi-lineage engraftment by a single bone marrow-derived stem cell. Cell 2001;105:369-377.

11. Lagasse $\mathrm{E}$, Connors $\mathrm{H}$, Al-Dhalimy $\mathrm{M}$, et al. Purified hematopoietic stem cells can differentiate into hepatocytes in vivo. Nat Med 2000;6: 1229-1234. 
12. Poulsom R, Forbes SJ, Hodivala-Dilke $\mathrm{K}$, et al. Bone marrow contributes to renal parenchymal turnover and regeneration. J Pathol 2001;195:229-235.

13. Bruscia EM, Ziegler EC, Price JE, et al. Engraftment of donorderived epithelial cells in multiple organs following bone marrow transplantation into newborn mice. Stem Cells 2006;24: 2299-2308.

14. Houghton J, Stoicov C, Nomura S, et al. Gastric cancer originating from bone marrow-derived cells. Science 2004;306:1568-1571.

15. Chakraborty A, Lazova R, Davies $\mathrm{S}$, et al. Donor DNA in a renal cell carcinoma metastasis from a bone marrow transplant recipient. Bone Marrow Transplant 2004;34:183-186.

16. Cogle CR, Theise ND, Fu D, et al. Bone marrow contributes to epithelia cancers in mice and humans as developmental mimicry. Stem Cells 2007;25:1881-1887

17. Avital I, Moreira A, Downey RJ. The origin of epithelial neoplasms after allogeneic stem cell transplantation. Haematologica 2006;91:ELT07; author reply ELT06.

18. Herzog EL, Krause DS. Engraftment of marrow-derived epithelial cells: the role of fusion. Proc Am Thorac Soc 2006;3:691-695.

19. Friedenstein AJ, Chailakhjan RK, Lalykina KS. The development of fibroblast colonies in monolayer cultures of guinea-pig bone marrow and spleen cells. Cell Tissue Kinet 1970;3:393-403.

20. Pittenger MF, Mackay AM, Beck SC, et al. Multilineage potential of adult human mesenchymal stem cells. Science 1999;284:143-147.

21. Friedenstein AJ, Chailakhyan RK, Latsinik NV, et al. Stromal cells responsible for transferring the microenvironment of the hemopoietic tissues. Cloning in vitro and retransplantation in vivo. Transplantation 1974;17:331-340.

22. Friedenstein AJ, Deriglasova UF, Kulagina NN, et al. Precursors for fibroblasts in different populations of hematopoietic cells as detected by the in vitro colony assay method. Exp Hematol 1974; 2:83-92.

23. Ferrari G, Cusella-De Angelis G, Coletta M, et al. Muscle regeneration by bone marrow-derived myogenic progenitors. Science 1998;279:1528-1530.

24. Rojas M, Xu J, Woods CR, et al. Bone marrow-derived mesenchymal stem cells in repair of the injured lung. Am J Respir Cell Mol Biol 2005;33:145-152.

25. Mackenzie TC, Shaaban AF, Radu A, et al. Engraftment of bone marrow and fetal liver cells after in utero transplantation in MDX mice. J Pediatr Surg 2002;37:1058-1064.

26. Cho KJ, Trzaska KA, Greco SJ, et al. Neurons derived from human mesenchymal stem cells show synaptic transmission and can be induced to produce the neurotransmitter substance $P$ by interleukinalpha. Stem Cells 2005;23:383-391.

27. Pittenger MF, Martin BJ. Mesenchymal stem cells and their potential as cardiac therapeutics. Circ Res 2004;95:9-20. Review.

28. Mackenzie TC, Flake AW. Multilineage differentiation of human MSC after in utero transplantation. Cytotherapy 2001;3: 403-405.

29. Anjos-Afonso F, Bonnet D. Nonhematopoietic/endothelial SSEA-1+ cells define the most primitive progenitors in the adult murine bone marrow mesenchymal compartment. Blood 2007;109: 1298-1306.

30. Jiang $\mathrm{Y}$, Jahagirdar $\mathrm{BN}$, Reinhardt $\mathrm{RL}$, et al. Pluripotency of mesenchymal stem cells derived from adult marrow. Nature 2002;418:41-49.

31. Nadri S, Soleimani M, Kiani J, et al. Multipotent mesenchymal stem cells from adult human eye conjunctiva stromal cells. Differentiation 2007;76:223-231.

32. D'lppolito G, Diabira S, Howard GA, et al. Marrow-isolated adult multilineage inducible (MIAMI) cells, a unique population of postnatal young and old human cells with extensive expansion and differentiation potential. J Cell Sci 2004;117:2971-2981.

33. Moll R, Franke WW, Schiller DL, et al. The catalog of human cytokeratins: patterns of expression in normal epithelia, tumors and cultured cells. Cell 1982;31:11-24.

34. Michel M, Torok N, Godbout MJ, et al. Keratin 19 as a biochemical marker of skin stem cells in vivo and in vitro: keratin 19 expressing cells are differentially localized in function of anatomic sites, and their number varies with donor age and culture stage. J Cell Sci 1996;109:1017-1028.
35. Brembeck FH, Moffett J, Wang TC, et al. The keratin 19 promoter is potent for cell-specific targeting of genes in transgenic mice. Gastroenterology 2001;120:1720-1728.

36. Calnek D, Quaroni A. Changes in keratin expression during fetal and postnatal development of intestinal epithelial cells. Biochem J 1992;285(Part 3):939-946.

37. Calnek D, Quaroni A. Differential localization by in situ hybridization of distinct keratin mRNA species during intestinal epithelial cell development and differentiation. Differentiation 1993;53: 95-104.

38. Quaroni A, Calnek D, Quaroni E, et al. Keratin expression in rat intestinal crypt and villus cells. Analysis with a panel of monoclonal antibodies. J Biol Chem 1991;266:11923-11931.

39. Chun-mao H, Su-yi W, Ping-ping $L$, et al. Human bone marrow-derived mesenchymal stem cells differentiate into epidermal-like cells in vitro. Differentiation 2007:75:292-298.

40. Digirolamo CM, Stokes D, Colter D, et al. Propagation and senescence of human marrow stromal cells in culture: a simple colony-forming assay identifies samples with the greatest potential to propagate and differentiate. Br J Haematol 1999;107:275-281.

41. Colter DC, Class R, DiGirolamo CM, et al. Rapid expansion of recycling stem cells in cultures of plastic-adherent cells from human bone marrow. Proc Natl Acad Sci USA 2000;97:3213-3218.

42. Javazon EH, Colter DC, Schwarz EJ, et al. Rat marrow stromal cells are more sensitive to plating density and expand more rapidly from single-cell-derived colonies than human marrow stromal cells. Stem Cells 2001;19:219-225.

43. Phinney DG, Kopen G, Isaacson RL, et al. Plastic adherent stromal cells from the bone marrow of commonly used strains of inbred mice: variations in yield, growth, and differentiation. J Cell Biochem 1999;72:570-585.

44. Kadiyala S, Young RG, Thiede MA, et al. Culture expanded canine mesenchymal stem cells possess osteochondrogenic potential in vivo and in vitro. Cell Transplant 1997;6:125-134.

45. Martin DR, Cox NR, Hathcock TL, et al. Isolation and characterization of multipotential mesenchymal stem cells from feline bone marrow. Exp Hematol 2002;30:879-886.

46. Javazon EH, Beggs KJ, Flake AW. Mesenchymal stem cells: paradoxes of passaging. Exp Hematol 2004;32:414-425.

47. Owen M, Friedenstein AJ. Stromal stem cells: marrow-derived osteogenic precursors. Ciba Found Symp 1988;136:42-60.

48. Houghton J, Wang TC. Role of bone marrow-derived cells in gastro adenocarcinoma. In: Wang TC, Fox J, Giraud A (eds). The Biology of Gastric Cancers. Springer Science Press: New York, NY, 2009, pp 561-586.

49. Yoon YS, Wecker A, Heyd L, et al. Clonally expanded novel multipotent stem cells from human bone marrow regenerate myocardium after myocardial infarction. J Clin Invest 2005;115:326-338.

50. Reyes M, Lund T, Lenvik T, et al. Purification and ex vivo expansion of postnatal human marrow mesodermal progenitor cells. Blood 2001;98:2615-2625

51. Li H, Fan X, Kovi RC, et al. Spontaneous expression of embryonic factors and p53 point mutations in aged mesenchymal stem cells: A model of age-related tumorigenesis in mice. Cancer Res 2007;67:10889-10898.

52. Kuznetsov SA, Mankani MH, Gronthos S, et al. Circulating skeletal stem cells. J Cell Biol 2001;153:1133-1140.

53. Metcalf $D$. Formation in agar of fibroblast-like colonies by cells from the mouse pleural cavity and other sources. J Cell Physiol 1972;80: 409-419.

54. Piersma $\mathrm{AH}$, Ploemacher RE, Brockbank KG, et al. Migration of fibroblastoid stromal cells in murine blood. Cell Tissue Kinet 1985; 18:589-595.

55. Rochefort GY, Delorme B, Lopez A, et al. Multipotential mesenchymal stem cells are mobilized into peripheral blood by hypoxia. Stem Cells 2006;24:2202-2208.

56. Kassis I, Zangi L, Rivkin R, et al. Isolation of mesenchymal stem cells from G-CSF-mobilized human peripheral blood using fibrin microbeads. Bone Marrow Transplant 2006;37:967-976.

57. Juliano RL, Haskill S. Signal transduction from the extracellular matrix. J Cell Biol. 1993;120:577-585.

58. van den Brink GR, Hardwick JC, Tytgat GN, et al. Sonic hedgehog regulates gastric gland morphogenesis in man and mouse. Gastroenterology. 2001;121:317-328. 
59. Halttunen T, Marttinen A, Rantala I, et al. Fibroblasts and transforming growth factor beta induce organization and differentiation of T84 human epithelial cells. Gastroenterology 1996;111:1252-1262.

60. Dignass AU, Tsunekawa S, Podolsky DK. Fibroblast growth factors modulate intestinal epithelial cell growth and migration.

Gastroenterology 1994;106:1254-1262.

61. Fritsch C, Swietlicki EA, Lefebvre O, et al. Epimorphin expression in intestinal myofibroblasts induces epithelial morphogenesis. J Clin Invest 2002;110:1629-1641.

62. Montesano R, Matsumoto K, Nakamura T, et al. Identification of a fibroblast-derived epithelial morphogen as hepatocyte growth factor. Cell. 1991;67:901-908.
63. Narita T, Saitoh K, Kameda T, et al. BMPs are necessary for stomach gland formation in the chicken embryo: a study using virally induced BMP-2 and Noggin expression. Development. 2000;127: 981-988.

64. Swenson ES, Price JG, Brazelton T, et al. Limitations of green fluorescent protein as a cell lineage marker. Stem Cells 2007;25: 2593-2600.

65. Okabe M, Ikawa M, Kominami K, et al. Green mice' as a source of ubiquitous green cells. FEBS Lett 1997;407:313-319.

66. Fox JG, Blanco M, Murphy JC, et al. Local and systemic immune responses in murine Helicobacter felis active chronic gastritis. Infect Immun 1993;61:2309-2315. 